\title{
PLATO AND THE CITY
}

Resenha crítica de: CORNELLI, Gabriele; LISI, Francisco L. (ed.). Plato and the city. St. Augustin dei Bonn: Academia Verlag, 2010. 146p. [ISBN: 978-3-89665-492-2]

Flávio R. Kothe ${ }^{1}$

Sinal dos tempos de globalização, o livro Plato and the City, editado por Gabriele Cornelli, da Universidade de Brasília, e Francisco Lisi, da Universidade Carlos III de Madrid, está em inglês, recheado de citações em grego, foi publicado em 2010 na Academia Verlag de Sankt Augustin da Alemanha, sobre Platão e a cidade. Não há um urbanista no elenco, mas professores de filosofia antiga. Se queriam apenas "especialistas", poderiam ter deixado o latim atual, a língua inglesa, e escrito o livro em grego. Sinal dos tempos: não só o intelectual brasileiro, mas também o espanhol, o italiano ou o francês que quiser dar uma contribuição para o mundo, precisa publicar em inglês. Quem escreve em português, parece estar morto de antemão para o mundo da ciência, da arte e da teoria. Não se trata aqui de bater no peito e se orgulhar da língua portuguesa. Ela resulta de uma dupla derrota e uma dupla prepotência: derrota dos povos ibéricos invadidos pelos romanos; derrota dos povos indígenas pela invasão lusitana; prepotência romana sobre as pro-víncias (regiões vencidas), prepotência senhorial lusa sobre a língua geral que se falou no Brasil até o século XVIII.

Se o livro foi publicado em inglês para um mundo dito latino, cabe examinar se ele merece o temor reverencial do neolatim da hegemonia atual. Caberá ver a que nos leva essa interiorização da dominação alheia. Está-se discutindo a questão da justiça nas relações sociais, o direito que o filósofo se atribui não só para dizer o que ela é, mas transformar sua definição em prática de governo. Está em jogo, portanto, a pretensão do filósofo de se considerar dono da verdade e formar uma casta governamental. O ponto nevrálgico disso está no Livro VII da República, conhecido como "mito da caverna", o que leva a releitura dessa obra de trás para diante, dando prioridade ao seu "fecho de ouro", o momento em que Sócrates desmonta todo o sistema proposto.

\footnotetext{
* Flávio R. Kothe é professor titular de Estética na FAU/UnB, autor de obras sobre o cânone literário brasileiro, a narrativa trivial, a teoria literária e a arte comparada, tradutor de Nietzsche, Marx, Kafka, Benjamin, Adorno, Habermas e outros, autor de poemas, contos e novelas.
} 
O que menos se deve fazer, no entanto, é mitificar e mistificar essa alegoria estendida, essa parábola do "mito da caverna". Assim como, em vez de fazer de Platão um monopólio de helenistas, teria sido estratégico levar em conta o que um urbanista teria a dizer quanto à visão dele sobre a cidade, não teria sido nocivo o olhar de um literato. Professores de filosofia tendem a ver em Platão apenas um filósofo, quando, antes de mais nada e sobretudo, ele é um escritor. Isso pode parecer pouco, parecer inferior, para quem afirma em alta voz que Nietzsche não é um filósofo e sim apenas um escritor. A pergunta que se impõe é o que fica aí escondido, o que não se quer que seja dito.

Isso se torna ainda mais difícil de expor numa "resenha", da qual se espera que ela seja uma propaganda do livro, pois é isso o que impera no país. Não há mais crítica literária no Brasil. Os espaços na mídia são tomados por poucas editoras grandes, que divulgam aí seus livros, ignorando os dos concorrentes. Não há também mais crítica de cinema nem cadernos de ideias no Brasil. Estranhamente, havia mais liberdade para esse tipo de crítica nos pérfidos tempos da ditadura militar do que hoje, tempos ditos de democracia. Quando a censura foi encerrada oficialmente em 1985, ela se interiorizou na mídia e se deixou de ter a frente ampla pela liberdade de expressão que reunia intelectuais de segmentos diversos durante a ditadura, gerando nichos críticos.

Olhando a extensa bibliografia publicada no final do livro, p. 125 a 131, ficam evidentes duas ausências sintomáticas, como se não tivessem nada a dizer sobre Platão e nunca tivessem dito nada crucial: Nietzsche e Heidegger. Tratei de retomar proposições deles num capítulo sobre "a alegoria da caverna", no livro Fundamentos da teoria literária, publicado em 2002 pela Editora da Universidade de Brasília, mas que já havia sido escrito quinze anos antes. Não se trata de vaidade, mas de retomar um ponto central, já tornado público e que desloca a discussão. Não adianta ignorar o que já foi dito e que altera de modo fundamental a temática, fazendo-se de conta que a discussão pode ser mantida nos termos da conveniência conivente. Ser professor de filosofia não é ser filósofo. Aliás, os grandes filósofos não fizeram doutorado em filosofia, não poderiam lecionar nos cursos de filosofia que deveriam estudar suas obras.

Quando se retoma um grande filósofo, a tendência dominante é diluir seus questionamentos, divinizar algumas assertivas, ser peão de seu rodeio, em vez de pegar o pião dos problemas na unha e tratar de pensá-lo adiante. As grandes obras guardam em si uma diferença, um abismo, entre o que elas puderam dizer e aquilo 
que elas gostariam de ter dito, mas apenas conseguiram sugerir. Se o leitor não conseguir penetrar nesse reino da diferença e recriar seu imaginário, ele não vai captar os impulsos e as pulsões que movem a obra e constituem o estatuído. Ele não vai conseguir pensar adiante, sem pensar adiante não vai conseguir chegar ao que foi pensado.

Qual é a pólis que existe dentro da caverna? Ela é um resumo da sociedade grega e de todas as sociedades de classe. Divide-se entre uma minoria de senhores ociosos e uma maioria de serviçais de dois tipos. Os ociosos são alimentados e cuidados por escravos e ficam olhando o cinema das sombras projetadas na parede a partir de uma fogueira nos fundos. Há "artistas", titiriteiros ou bonequeiros, que movimentam figuras e imitam vozes: eles se enquadram entre os serviçais. Tanto as figuras quanto as vozes copiam entes que existem fora da caverna. Para fazer isso, os "copistas" precisariam ter saído da caverna e visto como é o mundo lá fora. Isso não é, porém, lembrado na argumentação do "filósofo", embora esteja contido na fábula.

A fogueira deve ser alimentada provavelmente por madeira, já que não há a menor referência a uma fonte de petróleo permanente na caverna. Árvores não crescem dentro de cavernas. Os escravos precisariam sair da caverna para buscar a madeira. É muito provável que tenham de ir lá também a fim de arranjar alimentos para si e para seus senhores, pois seria absurdo que comessem apenas musgo e cogumelos.

No discurso de Sócrates, sem contradição do coroinha Glauco, é apenas entre os ociosos que há de surgir alguém que se liberte das cadeias e vá até lá fora, vendo a maravilha do sol como centro do universo (essa bobagem é postulada como verdade absoluta em contrapartida à doxa do geocentrismo). A saída necessária dos artistas e a dos escravos não é considerada. Oficialmente ela nem acontece. O filósofo só pode aí surgir entre os aristocratas, jamais entre os que trabalham. Ele quer ser aristocrata sendo filósofo, ele quer ser servido, ele quer mandar. Sabe-se o estrago que essa proposta de meritocracia fez à razão crítica ao ser implantada como estrutura da Igreja Católica.

Quando se transforma uma história em mito, ela é sacralizada, tornada tabu, não pode mais ser questionada em suas contradições, omissões, errâncias. A exegese trata de acobertá-las, fala do menor como se fosse maior, deixa o maior de fora, distorce, finge, mente. A hermenêutica filosófica deveria ser o contrário disso, mas continua presa à exegese teológica. Quem julga os juízes? Qual é o mérito do mérito? 
Na República, o filósofo não é alguém que ama o saber: ele ama, antes e acima de tudo, o poder. Por isso participa da mentira. Ele finge que nem os artistas nem os que trabalham já saíram antes dele da caverna, que ele é o primeiro e único e, por isso, merece o poder. Ora, o poder ele já tinha, estava entre os que eram servidos, o que ele propõe é uma nova casta sacerdotal no poder, a dos pseudofilósofos. Não é irônico, e ainda mais eficaz, que essa proposição seja feita por Sócrates, que não tinha origem aristocrática? Por que um filósofo não pode surgir entre os que trabalham? Não foi Kant filho de um carpinteiro?

Quando Heidegger examinou o mito da caverna, insistiu muito no perigo que o filósofo corre quando se dispõe a libertar seus antigos companheiros das cadeias que os prendem. Eles não querem ser libertados. Eles preferem continuar no estado de alienação. O pressuposto é, porém, que o filósofo realmente sabe o que é a verdade, que ele está acima da doxa da plebe e dos demais contemplativos. O que ele tem por verdade é, no entanto, mais um erro, que não se corrige com a assertiva de que o sol é apenas uma estrela de quinta grandeza, já que não se conhecem todas as estrelas. Supor que a verdade seja um "desencobrimento" sugere que ela já tenha estado aí um dia, tendo apenas sido esquecida. Isso leva a fetichizar a etimologia como filosofia.

É uma grande ruptura propor aí que a maioria dos membros da oligarquia não quer nada com nada, quer apenas ficar sendo servida, gozando uma vida vegetativa. Isso significa que não vai ter mérito todo aquele que tem sangue nobre, mas que é preciso ter sangue azul para poder ter mérito. É o mesmo que Sófocles postulou na trilogia tebana, quando aparentemente ousou propor que fosse alçado ao poder alguém que mostrou ter mais mérito do que os demais, mas que acaba se revelando como filho do antigo rei. É um reformismo que nada tem de revolucionário. O erro da aristocracia não faz, todavia, com que o "povo" esteja certo, que dele emana toda a verdade: a Terra continua não sendo o centro do universo, já porque não há universo nem centro. Só não há classe baixa porque a alta não é elevada.

Se o "filósofo" nega o seu nome e não é amigo da verdade, mas como qualquer político apenas usa o discurso para chegar ao poder, ele não tem "mérito" maior, ele não representa a verdade. Por isso, é preciso desconfiar de toda a sua argumentação, mesmo quando se supõe que haja algo como um princípio de justiça, e que a justiça não se deve confundir com a vontade do mais forte. A República precisa ser relida pelo avesso. Assim como a Bíblia, ela deve ser dessacralizada para ser entendida 
como a ficção que ela é. Isso acaba com o tabu e o temor reverencial, mas permite estabelecer outro tipo de diálogo e reconhecer outra grandeza, a literária.

Sócrates propõe a existência de um mundo das ideias do qual os entes reais seriam cópias, mas, no fim, quando propõe a Glauco andar pelo campo com um imenso espelho, ele sugere que existem primeiro as coisas reais e só depois o reflexo delas na mente humana. Numa obra que é basicamente uma criação ficcional, ele elogia Homero como grande poeta, para depois dizer que ele teria de ser expulso da cidade ideal, já que os artistas ficam inventando outros mundos. Ora, com isso ele acaba questionando e desconstruindo tudo o que havia proposto. Se Homero merece ser preservado, é problemática a proposição de um Estado totalitário, que não dê liberdade ao artista, em que um artista como Homero não possa ter espaço (como não tem na escola brasileira).

Questões centrais como essas aqui aventadas a título exemplificativo, pouco vi propriamente discutidas e levadas adiante pelos autores que compõem essa antologia (que é, aliás, muito boa para o relatório da CAPES e o currículo Lattes). Quando eles beiram alguma questão, em vez de pensarem por conta própria adiante, em geral recuam e tratam de ver o que o Mestre disse. Uma coisa é, porém, o que Sócrates diz, outra o que ele pensa sobre o que diz, uma terceira é o que Platão pensa sobre o que Sócrates pensa sobre o que Sócrates diz: maior é, no entanto, aquilo que o escritor Platão deixou entrever para que se pense adiante. Cada caixa maior altera a menor nela embutida. Em vez de ficar preso ao primeiro nível, teria sido melhor que os membros da antologia tivessem ousado ir para o quarto nível. 